\title{
A Survey of Bee Species Found Pollinating Watermelons in the Lower Rio Grande Valley of Texas
}

\author{
C. S. Henne, ${ }^{1}$ E. Rodriguez, ${ }^{1}$ and J. J. Adamczyk Jr. ${ }^{1,2}$ \\ ${ }^{1}$ Kika de la Garza Subtropical Agricultural Research Center, Beneficial Insects Research Unit, USDA, ARS, 2413 E. Hwy 83, Weslaco, \\ TX 78596, USA \\ ${ }^{2}$ Thad Cochran Southern Horticultural Laboratory, Southern Horticultural Research Unit, USDA, ARS, 810 Hwy 26W, P.O. Box 287, \\ Poplarville, MS 39470, USA
}

Correspondence should be addressed to J. J. Adamczyk Jr., john.adamczyk@ars.usda.gov

Received 27 October 2011; Revised 18 January 2012; Accepted 26 January 2012

Academic Editor: Shoil Greenberg

Copyright (๑) 2012 C. S. Henne et al. This is an open access article distributed under the Creative Commons Attribution License, which permits unrestricted use, distribution, and reproduction in any medium, provided the original work is properly cited.

Using a combination of flower traps and visual observations, we surveyed three watermelon (Citrullus lanatus (Thunb.) Matsum. \& Nakai) fields in the Lower Rio Grande Valley to determine what bees inhabit this crop in this region. No managed honey bee (Apis mellifera L.) hives were in any of the fields; however, two contained managed hives of the common eastern bumble bee, Bombus impatiens (Cresson). A total of 15 species were collected or observed from all three fields combined. Of these species, only four were found to be very abundant: Agapostemon angelicus Cockerell/texanus Cresson, A. mellifera, Lasioglossum coactum (Cresson), and Melissodes thelypodii Cockerell. Apis mellifera comprised 46\% of all bees collected from all three fields combined and was highly abundant in two of the three fields. In the third field, however, A. mellifera and Agapostemon angelicus/texanus were equally abundant. Surprisingly, B. impatiens comprised only $1 \%$ of the total bees surveyed in all three fields combined, despite two of the fields having several managed hives each. As B. impatiens is not native to this region, it was not surprising that none were collected or observed in the field with no managed hives.

\section{Introduction}

Watermelon [Citrullus lanatus (Thunb.) Matsum. \& Nakai; Cucurbitaceae] is a crop that has been well documented for its dependence on insect pollinators for fruit and seed set due to its monoecious flowering condition of separate staminate (male) and pistillate (female) flowers [1, 2]. In fact, numerous studies have even shown that watermelon plants in exclusion cages will not set fruit [1-3]. Each female watermelon flower also requires approximately 500 to 1000 or more viable pollen grains for complete fertilization of ovules $[1,4]$. Therefore, each female watermelon flower has been found to require at least 6-8 honey bee (Apis mellifera L.; Hymenoptera: Apidae) visits for successful pollination $[1,5]$.

Historically, A. mellifera has been generally recognized as the most important pollinator for commercial crop production $[4,5]$, including watermelon. Due to their manageability and large perennial colonies, A. mellifera is easily transported to different fields as needed [4-6]. Recently, however, many A. mellifera colonies have been significantly weakened or lost due to exotic parasites, diseases, loss of bee-keeping subsidies, colony collapse disorder, Africanization, and pesticide exposure [3-8]. In fact, the supply of $A$. mellifera colonies has been reduced more than $50 \%$ since the 1950 s despite a growing demand for Apis pollination services [4].

In response to declining $A$. mellifera populations, watermelon growers are now pollinating their fields using commercial bumble bees (Bombus spp.; Hymenoptera: Apidae). Although Bombus spp. have small annual colonies made up of fewer workers than A. mellifera hives have and they are also labor-intensive to produce, Bombus colonies require far less maintenance in the field. Moreover, their workers are active at lower temperatures and fly in higher winds than A. mellifera do. On a per-bee basis, Bombus spp. are also more efficient watermelon pollinators than A. mellifera are [6]. In USA, the primary commercial Bombus species is the common eastern bumble bee, B. impatiens (Cresson). 
Researchers and growers have recently turned their focus to evaluating wild bee species as pollinators in crop production, especially in crops that are heavily dependent on insect pollinators, such as watermelon, for example $[4,7,8]$. In certain crops, some wild bee species are more effective pollinators than are A. mellifera workers [4]. Also, wild bees provide their pollination services free of charge [7]. Kremen et al. [7] found that organic farms in California located near native habitat (defined as having $\geq 30 \%$ native habitat within a $1 \mathrm{~km}$ radius of the farm) could receive adequate pollination from wild bees alone. However, as agricultural intensification increases, pollination services decrease by 3 - to 6-fold [7].

Watermelon is one of many important crops grown in the Lower Rio Grande Valley of Texas. In an attempt to better understand watermelon pollination in the Lower Rio Grande Valley, bee species, both wild and managed, were surveyed at flowering watermelon in this region.

\section{Materials and Methods}

Observations and collections were undertaken in three fields located in Hidalgo County, TX, during Spring 2011. Two fields, designated as Mile 13 Field $\left(26.38881^{\circ} \mathrm{N}\right.$, $\left.98.23451^{\circ} \mathrm{W}\right)$ and Mile 14 Field $\left(26.40230^{\circ} \mathrm{N}, 98.23282^{\circ} \mathrm{W}\right)$, located northwest of Edinburg, TX, were the larger of the three fields at 3.237 ha and 7.284 ha, respectively. Both fields are owned by a local watermelon grower and were planted in mid-Feb. 2011 with both seeded and seedless varieties interplanted within each row. While neither of these fields had managed A. mellifera hives placed in them, they both did have multiple managed hives of $B$. impatiens. Native vegetation consisting predominantly of common sunflower (Helianthus annuus L.; Asteraceae) was allowed to grow along the field edges as a refuge for beneficial insects. Both of these fields had adjacent citrus orchards and grassy fields with remnant citrus trees and mesquite.

The third field (ARS Field) was a small solid planting ( $0.352 \mathrm{ha}$ ) of a seeded variety (Legacy) located on the USDAARS property in Weslaco, TX $\left(26.15850^{\circ} \mathrm{N}, 97.96364^{\circ} \mathrm{W}\right)$. This field was established a month later on 8 Mar. 2011. Native vegetation along the field edges was kept mowed, except for a $30 \mathrm{~m}$ strip of golden crownbeard (Verbesina encelioides (Cav.) Benth. \& Hook. F. ex A. Gray; Asteraceae) growing along a fence $\sim 30 \mathrm{~m}$ from the field's western edge. ARS Field was also bordered on the south side by a corn field. No managed A. mellifera or B. impatiens hives were placed in this field.

To target just the bees visiting watermelon flowers, flower traps were used primarily [9]. Traps consisted of clear $4.5 \mathrm{oz}$. Falcon specimen cups filled with approximately $80 \mathrm{~mL}$ of soapy water solution $(3 \mathrm{~mL}$ of liquid dishwashing soap/3.785 L of water). A single male watermelon flower was submerged in each trap during trap placement. A total of 10 points approximately $6 \mathrm{~m}$ apart were marked in each field along three $60 \mathrm{~m}$ transects for a total of 30 points per field. Transects began approximately $6 \mathrm{~m}$ from the field edge following the row. During peak watermelon flowering, traps were placed at each point between $0900 \mathrm{HR}$ and $1000 \mathrm{HR}$ and removed between $1400 \mathrm{HR}$ and $1430 \mathrm{HR}$. Contrary to findings in North Carolina where watermelon flowers opened around $0700 \mathrm{HR}$ [10], watermelon flowers in our study were just opening at the time of trap placement and were just about to close at the time of trap removal. All samples were brought back to the lab for processing and identification. Due to the short flowering period, Mile 13 Field and Mile 14 Field were sampled weekly a total of three times (31 Mar., 7 Apr., and 14 Apr.), and ARS Field was sampled weekly a total of five times (19 Apr., 26 Apr., 3 May, 10 May, and 17 May). A single trap was placed beside a single hive quad (Koppert Biological Systems, Inc.; Michigan, USA) at Mile 13 Field and Mile 14 Field (2 traps total) to see if traps would collect worker B. impatiens.

Trap samples were supplemented with visual observations and hand collections. During trap placement and removal, the surrounding flowers were scanned for the presence of bees. If a bee could be identified by sight, its identity and the location it was observed were recorded. If a bee could not be identified by sight, it was collected using a Dirt Devil Detailer (Model CV 2000) and brought back to the lab for processing and identification. To eliminate counting nonvisiting bees, only bees observed in watermelon flowers were recorded or collected. Approximately $1.5 \mathrm{~h}$ after trap placement on 14 Apr., sample points of Mile 13 Field were each visually surveyed for an additional period; however, additional visual observations were not made at either of the remaining fields.

All identifications were made by one of us ( $\mathrm{CSH})$ primarily using the identification keys provided on the Discover Life website (http://www.discoverlife.org/mp/20q? search=Apoidea). In cases where the Discover Life key to species for a specific genus did not cover the Lower Rio Grande Valley, an appropriate published key was used. Identification of Lasioglossum coactum (Cresson) (Hymenoptera: Halictidae) was aided with correspondence with Jason Gibbs, who also confirmed this identification after viewing representative specimens.

Due to morphological similarities between Agapostemon angelicus Cockerell and A. texanus Cresson (Hymenoptera: Halictidae), a definitive identification cannot be made without molecular testing [11]. Based on species collection records for both species mapped on the Discover Life website, it is likely that the correct identification is A. texanus. However, no males of either species, which are distinctly different, were collected to support this assumption.

\section{Results}

A total of 15 species of bees were collected from our watermelon fields in the Lower Rio Grande Valley (Table 1). ARS Field was found to be the most diverse field with 11 species. Eight and nine species of bees were collected from Mile 13 Field and Mile 14 Field, respectively. ARS Field had a higher overall abundance of bees than the other two fields, possibly a result of this field being sampled two more times than Mile 13 Field and Mile 14 Field.

Only four species were found to be abundant: $A$. angelicus/texanus, A. mellifera, L. coactum, and Melissodes thelypodii Cockerell (Hymenoptera: Apidae). Apis mellifera was 
TABLE 1: Bee species collected from three Lower Rio Grande Valley watermelon fields during 2011.

\begin{tabular}{|c|c|c|c|c|c|c|}
\hline \multirow{2}{*}{ Species } & \multicolumn{2}{|c|}{ ARS } & \multicolumn{2}{|c|}{ Mile 13} & \multicolumn{2}{|c|}{ Mile 14} \\
\hline & Traps & Obs. & Traps & Obs. & Traps & Obs. \\
\hline Agapostemon angelicus/texanus* & 1 & - & 12 & 1 & 38 & - \\
\hline Apis mellifera & 2 & 67 & 10 & 44 & 11 & 28 \\
\hline Augochlorella aurata & - & - & - & - & 1 & - \\
\hline Augochlorella bracteata & - & 1 & - & - & - & - \\
\hline Bombus impatiens & - & - & - & 3 & 1 & 1 \\
\hline Exomalopsis snowi & 1 & - & - & - & - & - \\
\hline Florilegus condignus & 1 & - & - & - & - & - \\
\hline Halictus ligatus & 3 & 2 & - & - & 1 & 1 \\
\hline Lasioglossum coactum & 38 & - & 5 & - & 6 & 1 \\
\hline Lasioglossum viridatum & - & - & - & - & 3 & - \\
\hline Lasioglossum sp. 1 & - & - & 1 & - & - & - \\
\hline Lasioglossum sp. 2 & 3 & - & 8 & - & 3 & - \\
\hline Lasioglossum spp. & - & 2 & - & - & - & - \\
\hline Melissodes thelypodii & 19 & 1 & 18 & 1 & 8 & 1 \\
\hline Nomada crucis & - & 1 & - & - & - & - \\
\hline Triepeolus helianthi & 3 & 1 & 1 & - & - & - \\
\hline Unknown Halictid & - & 1 & - & - & - & - \\
\hline Total: & 71 & 76 & 55 & 49 & 72 & 32 \\
\hline Overall Total: & \multicolumn{2}{|c|}{147} & \multicolumn{2}{|c|}{104} & \multicolumn{2}{|c|}{104} \\
\hline
\end{tabular}

*Females of A. angelicus and A. texanus are morphologically identical and cannot be separated where the distribution of the two species overlap [11].

the most abundant bee, comprising $46 \%$ of the overall total number of bees collected and observed from all three fields combined. Agapostemon angelicus/texanus, L. coactum, and M. thelypodii each comprised $13 \%$ to $15 \%$ of the overall total number of bees surveyed. The remaining 11 species collectively comprised the remaining 11\%. Despite Mile 13 Field and Mile 14 Field having approximately 3-4 managed hives of $B$. impatiens each, only 5 workers from these colonies were collected or observed from both fields. Bombus impatiens workers comprised only $1 \%$ of the overall total of bees surveyed from the three fields.

Apis mellifera was the most abundant pollinator in ARS Field and Mile 13 Field, while A. angelicus/texanus was equally abundant to $A$. mellifera in Mile 14 Field. Only one individual of $A$. angelicus/texanus was collected at ARS Field. However, $A$. angelicus/texanus numbers began to decline as the season progressed (Figure 1). Conversely, ARS Field had $3 \mathrm{x}$ the abundance of $L$. coactum than either of the two other fields combined, with a large peak in abundance on the last sample date (17 May) (Figure 1).

\section{Discussion}

Our results were similar to those found in a small survey near Leesburg, FL [12]: the most abundant species was A. mellifera, followed by three fairly abundant species and other less common species. In total, Goff [12] collected eight species of bees, which is approximately the number of species that were found in our study fields. However, with the exception of A. mellifera, the bees Goff [12]

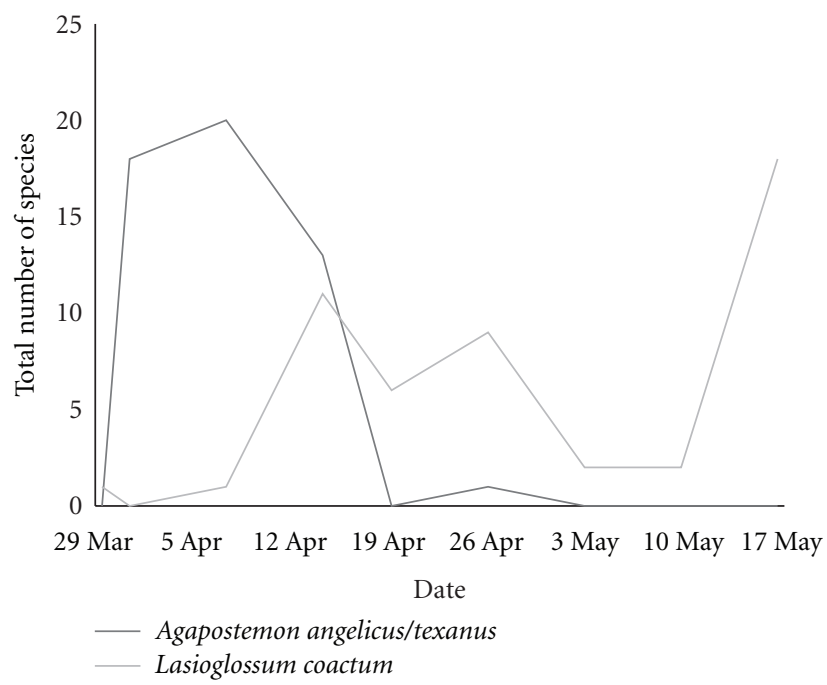

FIGURE 1: Seasonality of Agapostemon angelicus/texanus and Lasioglossum coactum collected from three Lower Rio Grande Valley watermelon fields during 2011.

collected were solely from the family Halictidae. Our study found roughly equal number of species from Halictidae and Apidae, including a few cleptoparasites presumably oudrinking nectar.

As no managed hives of A. mellifera were placed in any of these fields, the high number of this species collected and observed likely derives from feral colonies living nearby. 
Grassy habitats located in close proximity to our fields were observed to contain suitable nesting sites for feral $A$. mellifera. It is equally likely that some of these bees may have originated from managed hives that were observed in a grassy field approximately 1 to $2 \mathrm{~km}$ east of Mile 13 Field and Mile 14 Field. Previous studies have indicated that this distance is well within the typical foraging range of $A$. mellifera, for example [13, 14]. In fact, Visscher and Seeley [13] found the radius surrounding $95 \%$ of their observation colony's foraging sites to be $6 \mathrm{~km}$. Beekman and Ratnieks [14] found that $95 \%$ of the bees from their observation colony foraged within an even greater distance of $10 \mathrm{~km}$.

Porter [15] noted that A. texanus was frequently found in fields and open places in scrub and woodland, such as abandoned citrus groves in the Lower Rio Grande Valley. Populations of $A$. texanus most likely occur year-round, but its population appeared to peak in December and January before becoming scarce by March and May [15]. This seasonality may explain the relative lack of $A$. angelicus/texanus in ARS Field compared to Mile 13 Field and Mile 14 Field as ARS Field was sampled a month later than the other two fields due to a later planting date. Porter [15] also noted that the main nectar and pollen source for $A$. texanus was common sunflower, which may, again, contribute to the low abundance of $A$. angelicus/texanus in ARS Field. While Mile 13 Field and Mile 14 Field both had common sunflower growing abundantly along the edges, ARS Field did not.

Life history information is lacking for L. coactum, which belongs to the predominantly primitively eusocial subgenus Dialictus [16, 17]. Dialictus contains numerous, commonly collected, "morphologically monotonous" species $[17,18]$. In fact, a recent molecular study revealed that the easily identified species Lasioglossum tegulare (Robertson) (Hymenoptera: Halictidae) was instead a species complex containing several cryptic species, including L. coactum [17]. Gibbs [17] notes that the range of $L$. tegulare is more restricted to the northeast than previously reported and that records from Texas are probably L. coactum. As Dialictus tegularis, Mitchell [19] records a flight season of March or April through October for L. coactum.

The apparent higher abundance of $L$. coactum at ARS Field than Mile 13 Field and Mile 14 Field is likely a reflection of the later sampling at ARS Field than Mile 13 Field and Mile 14 Field. Primitively eusocial species tend to start with a single, solitary female completing all necessary nesting tasks. Upon emergence of her offspring, division of labor between queen and workers arises [20]. The lower number of $L$. coactum at both Mile 13 Field and Mile 14 Field are likely females just emerging from winter diapause at the beginning of the flight season. The increase at ARS Field likely reflects the natural increase in population as the season progresses. The drop in L. coactum abundance seen during early May could be attributed to residues from insecticides targeting whiteflies in late April. As we did not test for this, nor was this pesticide used on either of the two other fields, this relationship could also be coincidental.

Such a low abundance of $B$. impatiens both in the traps and during visual observations was surprising when considering the presence of multiple colonies at Mile 13
Field and Mile 14 Field. This was contrary to a study in North Carolina [10] looking at watermelon and cucumbers, which compared the diurnal activity, floral visitation rate, and pollen deposition rate of $B$. impatiens to A. mellifera to determine the most efficient pollinator of the two. Because B. impatiens was found to be out foraging earlier and longer, visited more flowers/minute and deposited more pollen grains, it was found to be the most efficient pollinator. However, no distinction was made in this study between managed and feral B. impatiens [10].

Bombus impatiens has a published distribution of Ontario and Maine, south to Florida, and west to Michigan, Illinois, Kansas, and Louisiana [21, 22]. The low abundance of $B$. impatiens in our study compared to the North Carolina study may be due to the fact that $B$. impatiens is not native to Texas or the Lower Rio Grande Valley as it is to North Carolina. Therefore, the managed colonies brought in from Michigan may not have been adequately adapted for the Lower Rio Grande Valley climate. In North Carolina, B. impatiens was found to be out foraging in watermelon flowers approximately $30 \mathrm{~min}$. earlier than A. mellifera and, in some cases, even attempting to forcibly enter unopened watermelon flowers. Both species were observed foraging until the watermelon flowers closed for the day [10]. While our traps were placed in the field later in the morning than those in North Carolina, we do not feel we missed early morning $B$. impatiens foraging in watermelon as our traps were placed at the time of flower opening. In fact, on at least one occasion, trap placement was delayed until the male flowers were open enough to be used in the traps.

Colored pan traps are a passive collection method with the advantage of limiting potential sampling biases associated with the sampler's observational and netting skills. However, they have been known to have several biases, one of which is that they catch fewer individuals of Bombus spp. than expected [23]. In an attempt to avoid these biases as well as target our catches to bees attracted to watermelon, we employed flower traps, which shift the attractant from bowl color to the target flower. While this study did not specifically test the traps for any biases, we do not believe that trap biases, if any, were a contributing factor in the low B. impatiens abundance at both Mile 13 Field and Mile 14 Field. Visual observation data as well as unrecorded observations made in these fields during nonsampling times also indicated low $B$. impatiens abundance.

This study was conducted solely with the intent to establish baseline knowledge of the bees present in Lower Rio Grande Valley watermelon fields. As no major surveys of the Lower Rio Grande Valley bee fauna had been undertaken previously, our prior expectations were limited to A. mellifera, based on surrounding vegetation types as well as Peponapis pruinosa (Say) (Hymenoptera: Apidae), due to its dependence on the flowers of other cucurbits (i.e., squash). Therefore, the relatively high abundance of $A$. mellifera was not very surprising. Neither was the relatively high abundance of L. coactum as the genus Lasioglossum is globally occurring, commonly collected, and well known to dominate faunas with its abundance [18]. The most surprising finding of this study was the low abundance of 
B. impatiens at Mile 13 Field and Mile 14 Field despite having managed hives within these fields.

\section{Acknowledgments}

The authors would like to thank their grower, Mr. Bob Dyer, for use of his fields. They would also like to thank Dr. Jason Gibbs for his assistance in the identification of Lasioglossum (Dialictus) coactum. Reviews by Dr. Rosalind James, Dr. Don Thomas, Dr. Blair Sampson, and Dr. Don Henne greatly improved this paper.

\section{References}

[1] W. C. Adlerz, "Honey bee numbers and watermelon pollination," Journal of Economic Entomology, vol. 59, no. 1, pp. 28 30, 1996.

[2] J. B. Free, Insect Pollination of Crops, Academic Press, San Diego, Calif, USA, 2nd edition, 1993.

[3] M. S. Stanghellini, J. T. Ambrose, and J. R. Schultheis, "Seed production in watermelon: a comparison between two commercially available pollinators," HortScience, vol. 33, no. 1, pp. 28-30, 1998.

[4] C. Kremen, R. L. Bugg, N. Nicola, S. A. Smith, R. W. Thorp, and N. M. Williams, "Native bees, native plants, and crop pollination in California," Fremontia, vol. 30, no. 3-4, pp. 4149, 2002.

[5] M. S. Stanghellini, J. T. Ambrose, and J. R. Schultheis, "The effects of honey bee and bumble bee pollination on fruit set and abortion of cucumber and watermelon," American Bee Journal, vol. 137, no. 5, pp. 386-391, 1997.

[6] M. S. Stanghellini, J. T. Ambrose, and J. R. Schultheis, "Using commercial bumble bee colonies as backup pollinators for honey bees to produce cucumbers and watermelons," HortTechnology, vol. 8, no. 4, pp. 590-594, 1998.

[7] C. Kremen, N. M. Williams, and R. W. Thorp, "Crop pollination from native bees at risk from agricultural intensification," Proceedings of the National Academy of Sciences of the United States of America, vol. 99, no. 26, pp. 16812-16816, 2002.

[8] R. Winfree, N. M. Williams, H. Gaines, J. S. Ascher, and C. Kremen, "Wild bee pollinators provide the majority of crop visitation across land-use gradients in New Jersey and Pennsylvania, USA," Journal of Applied Ecology, vol. 45, no. 3, pp. 793-802, 2008.

[9] S. Droege, "The very handy manual: how to catch and identify bees and manage a collection," USGS Native Bee Inventory and Monitoring Lab http://bees.tennessee.edu/publications/ HandyBeeManual.pdf.

[10] M. S. Stanghellini, J. T. Ambrose, and J. R. Schultheis, "Diurnal activity, floral visitation and pollen deposition by honey bees and bumble bees on field-grown cucumber and watermelon," Journal of Apicultural Research, vol. 41, no. 1-2, pp. 27-34, 2002.

[11] R. B. Roberts, "Revision of the bee genus Agapostemon (Hymenoptera: Halictidae)," The University of Kansas Science Bulletin, vol. 44, no. 9, pp. 437-590, 1972.

[12] C. G. Goff, "Importance of bees in the production of watermelons," Florida Entomologist, vol. 20, no. 2, pp. 30-31, 1937.

[13] P. K. Visscher and T. D. Seeley, "Foraging strategy of honeybee colonies in a temperate deciduous forest," Ecology, vol. 63, no. 6, pp. 1790-1801, 1982.
[14] M. Beekman and F. L. W. Ratnieks, "Long-range foraging by the honey-bee, Apis mellifera L.," Functional Ecology, vol. 14, no. 4, pp. 490-496, 2000.

[15] C. C. Porter, "Ecological notes on Lower Rio Grande Valley Augochloropsis and Agapostemon (Hymenoptera: Halictidae)," The Florida Entomologist, vol. 66, no. 3, pp. 344-353, 1983.

[16] B. N. Danforth, L. Conway, and S. Ji, "Phylogeny of eusocial Lasioglossum reveals multiple losses of eusociality within a primitively eusocial clade of bees (Hymenoptera: Halictidae)," Systematic Biology, vol. 52, no. 1, pp. 23-36, 2003.

[17] J. Gibbs, "Integrative taxonomy identifies new (and old) species in the Lasioglossum(Dialictus) tegulare (Robertson) species group (Hymenoptera, Halictidae)," Zootaxa, no. 2032, pp. 1-38, 2009.

[18] J. Gibbs, "Atypical wing venation in Dialictus and Hemihalictus and its implications for subgeneric classification of Lasioglossum," Psyche, vol. 2010, Article ID 605390, 6 pages, 2010.

[19] T. B. Mitchell, "Bees of the Eastern United States," Vol. I. North Carolina Agricultural Experiment Station Technical Bulletin, vol. 141, 538 pages, 1960.

[20] C. D. Michener, The Bees of the World, Johns Hopkins University Press, Baltimore, Md, USA, 2nd edition, 2007.

[21] T. B. Mitchell, "Bees of the Eastern United States," Vol. II. North Carolina Agricultural Experiment Station Technical Bulletin, vol. 152, 557 pages, 1962.

[22] K. V. Krombien, P. D. Hurd, D. R. Smith, and B. D. Burks, Catalog of Hymenoptera in America North of Mexico, vol. 2, Smithsonian Institution Press, Washington, DC, USA, 1979.

[23] T. H. Roulston, S. A. Smith, and A. L. Brewster, "Short communication: a comparison of pan trap and intensive net sampling techniques for documenting a bee (Hymenoptera: Apiformes) fauna," Journal of the Kansas Entomological Society, vol. 80, no. 2, pp. 179-181, 2007. 

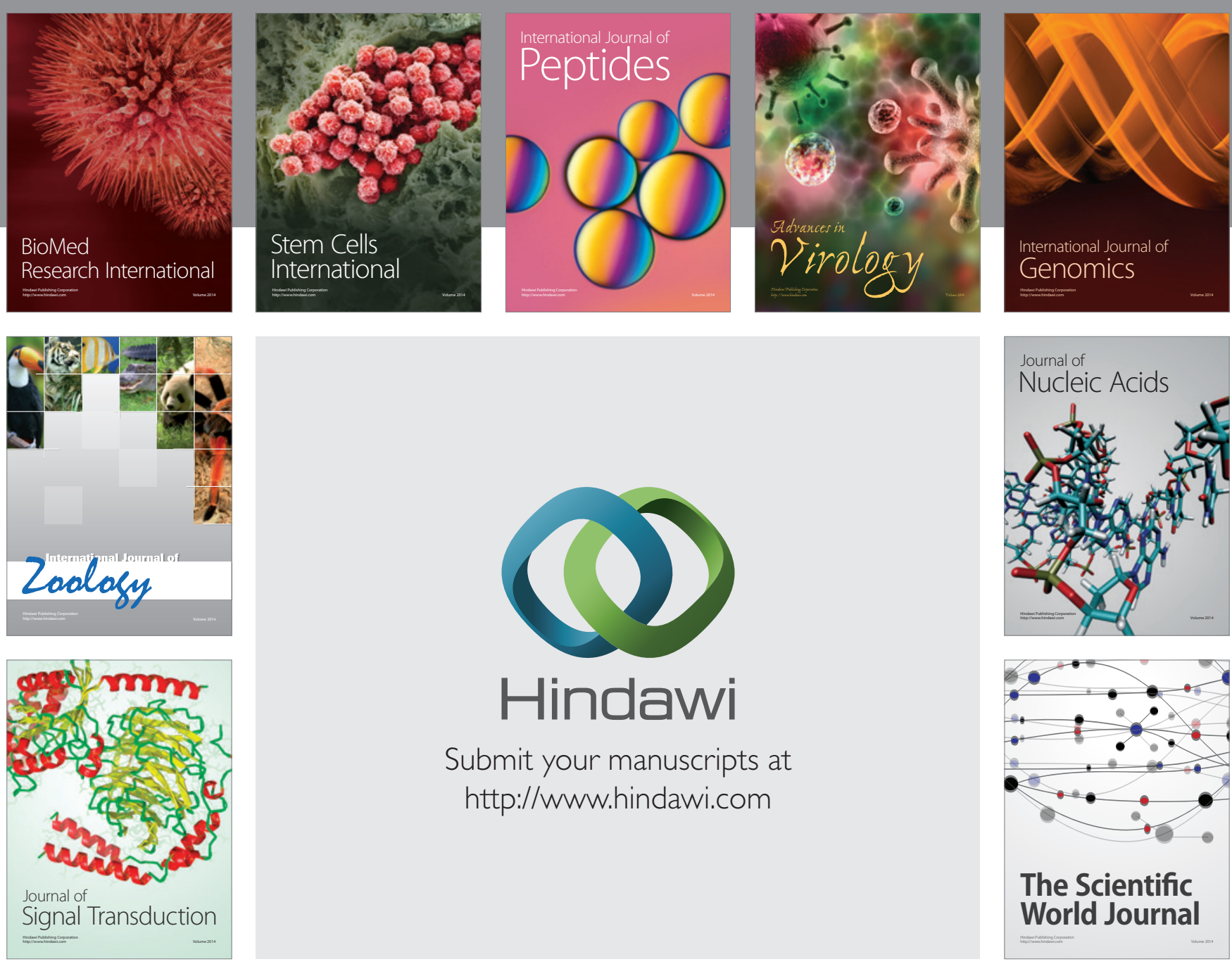

Submit your manuscripts at

http://www.hindawi.com
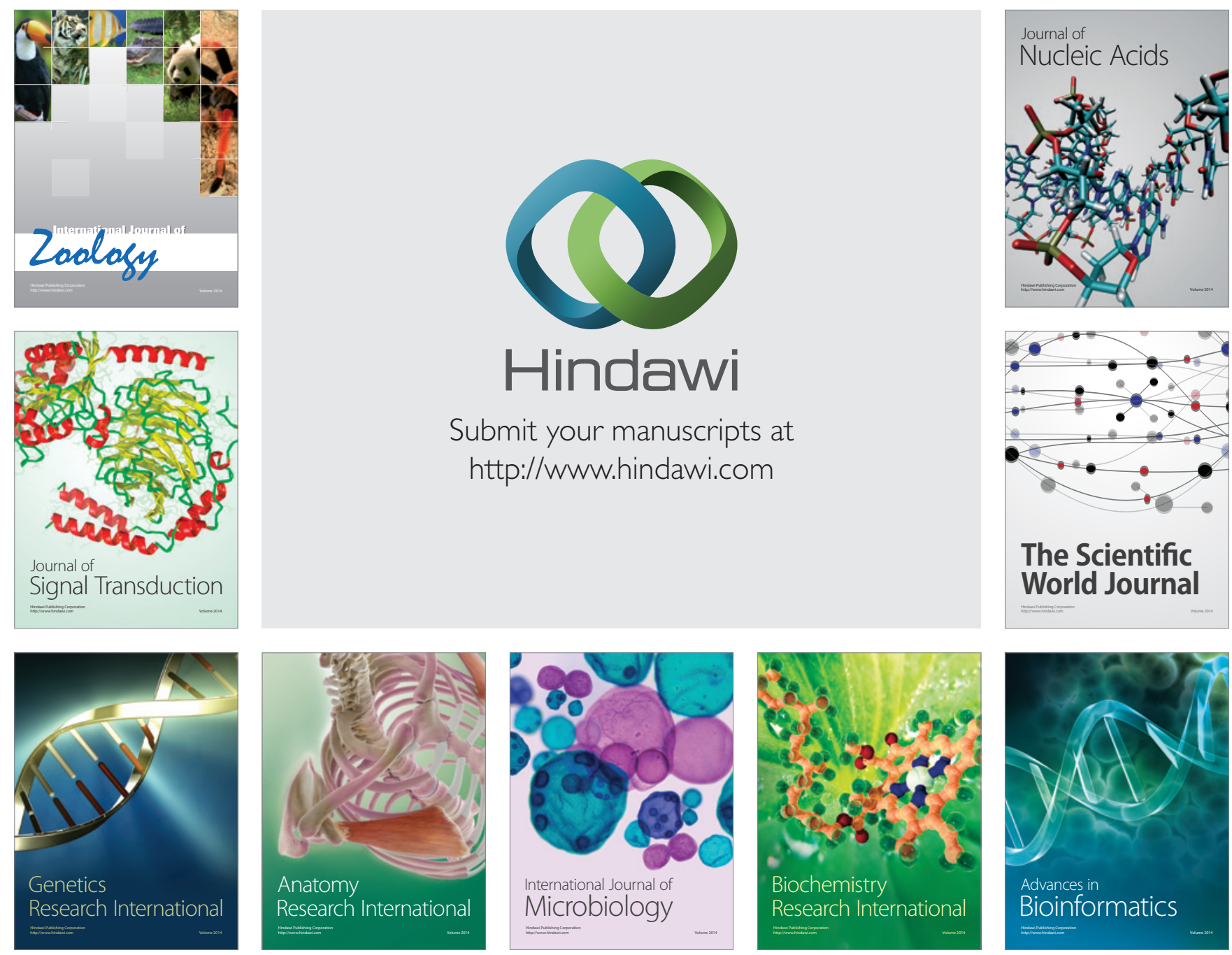

The Scientific World Journal
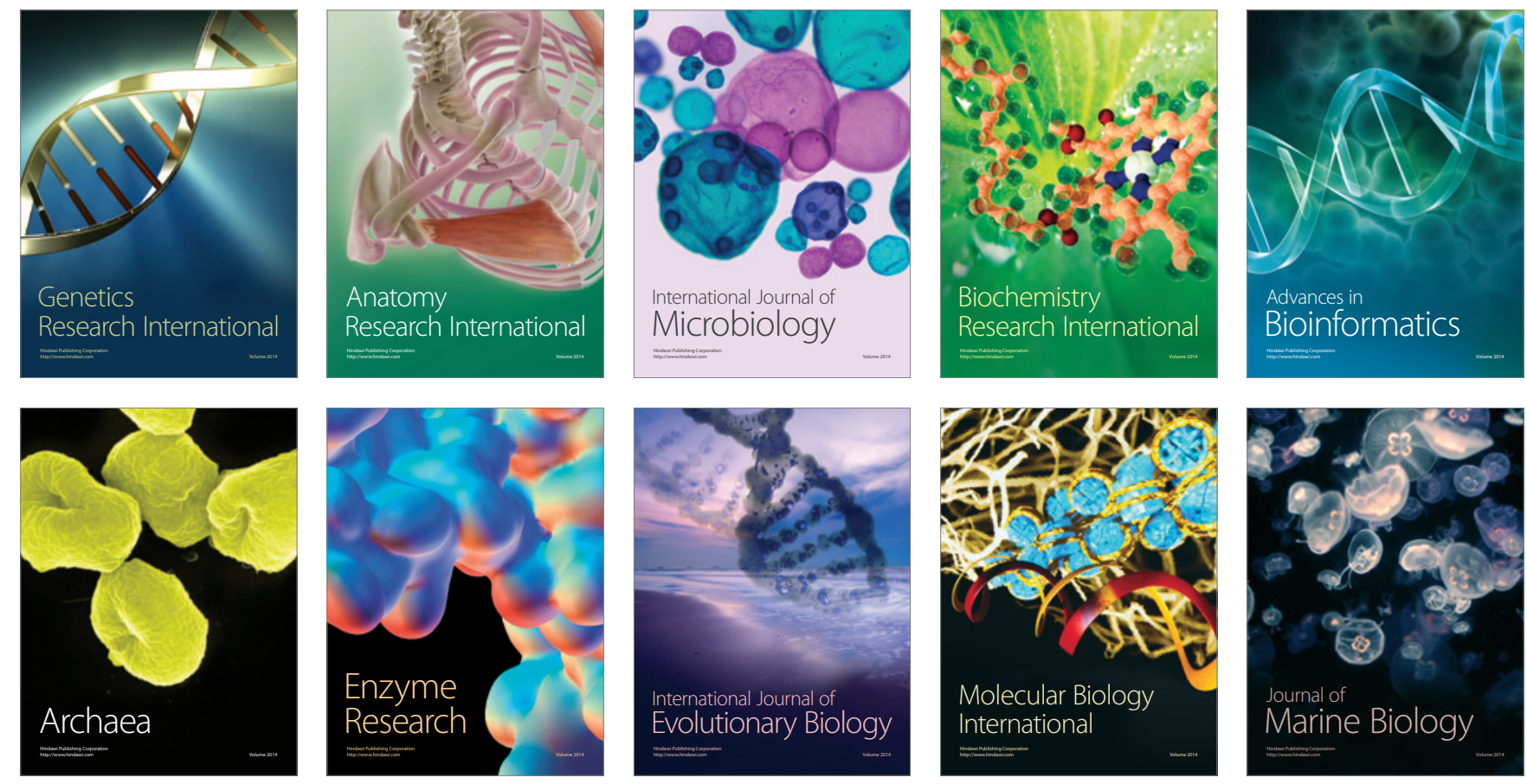